\title{
Attenuation of hypertensive response with esmolol and labetalol in low doses in orotracheal intubation: A comparative study
}

\author{
Suruchi Ambasta ${ }^{1, *}$, Swagat Mahapatra ${ }^{2}$ \\ Assistant Professor, ${ }^{1}$ Dept. of Anaesthesia, Mayo Institute of Medical Sciences, Lucknow, Uttar Pradesh, ${ }^{2}$ Dept. of Orthopaedics, \\ Dr. Ram Manohar Lohia Institute of Medical Sciences, Lucknow, Uttar Pradesh, India
}

*Corresponding Author:

Email: suruchi0904@gmail.com

Received: $07^{\text {th }}$ October, 2017

Accepted: $14^{\text {th }}$ December, 2017

\begin{abstract}
Introduction: This was a prospective, randomized, double blind, comparative, clinical study to assess the efficacy of Esmolol and Labetalol, in low doses, for attenuation of sympathomimetic response to laryngoscopy and intubation.

Materials and Methods: This study was conducted on 50 ASA 1 patients of either sex undergoing elective surgeries under general anaesthesia. Patients were randomized into two groups; group E who received intravenous Esmolol $(0.5 \mathrm{mg} / \mathrm{kg}) \mathrm{or}$ group $\mathrm{L}$ who received intravenous Labetalol $(0.25 \mathrm{mg} / \mathrm{kg})$ prior to induction and hemodynamic parameters were recorded as per designed protocol to assess stress response to laryngoscopy and intubation.

Results: Both the study groups had similar demographic profile. Instat version 3.10 was used for statistical calculations. The study data were analyzed using statistical methods of mean, standard deviation. Esmolol $(0.5 \mathrm{mg} / \mathrm{kg}), \mathrm{abetalol}(0.25 \mathrm{mg} / \mathrm{kg})$ significantly attenuated the rise in heart rate, systolic blood pressure, and RPP during laryngoscopy and intubation. However, the difference was not statistically significant among the values for DBP and MAP.

Conclusion: From our clinical study it can be concluded that in lower doses, intravenous Labetalol $(0.25 \mathrm{mg} / \mathrm{kg})$ is a better agent than intravenous Esmolol $(0.5 \mathrm{mg} / \mathrm{kg})$ in attenuating the sympathomimetic response to laryngoscopy and intubation. Usual dose of esmolol used to obtund intubation response is $2-4 \mathrm{mg} / \mathrm{kg}$, while labetalol has been tried in all doses ranging from $0.25,0.5$, 0.75 , and $1 \mathrm{mg} / \mathrm{kg} .{ }^{17}$
\end{abstract}

Keywords: Esmolol, Labetalol, Stress response, Laryngoscopy and Intubation.

\section{Introduction}

Despite the emergence of new airway devices in the recent years, rigid laryngoscopy and tracheal intubation still remains the gold standard in airway management. The major conditions in which the hemodynamic changes may pose serious challenges are cardiovascular diseases like hypertension, coronary artery disease, vascular aneurysms. Sudden hemodynamic changes may lead to left ventricular failure and myocardial ischemia in these patients. Those with decreased intracranial compliance and increased intracranial pressure like intracranial tumors or cerebral hematomas may collapse due to cerebral hemorrhage. Circulatory effects of laryngoscopy and intubation like reflex tachycardia and hypertension are marked in many patients. ${ }^{1}$ Cardiovascular response to laryngoscopy and intubation is a reflex phenomenon with afferent stimuli carried by Glossopharyngeal nerve and Vagal pathways which activate suprasegmental and hypothalamic sympathetic centers to cause peripheral sympathoadrenal responses with release of Adrenaline and Noradrenaline. ${ }^{2}$ Blood pressure elevation is due to Norepinephrine whereas changes in heart rate are Epinephrine related. ${ }^{2}$ Beta blockers with bradycardiac, antihypertensive, antiarrythmic and antiischemic properties are found to have role in preventing cardiovascular stress response to intubation.
This reflex hemodynamic changes are better tolerated in health, but they are greatly exaggerated and detrimental in patients with comorbidities. ${ }^{1}$ Various pharmacological attempts have been made to obtund the pressor response. Volatile inhalational agents, intravenous Lignocaine, intravenous Opioids like Fentanyl, Alfentanil, Remifentanivasodilators like Sodium Nitroprusside, Nitroglycerine, calcium channel blockers like Verapamil, Diltiazem and adrenergic blockers like Clonidine are widely used. Several studies on intravenous Esmolol and intravenous Labetalol given preoperatively showed effectiveness in decreasing stress response. Esmolol is a cardio selective $\mathrm{b}_{1}$-blocker having rapid onset and short duration of action. It causes depressor effect on myocardium; therefore, its place still remains to be defined especially in cardiac risk patients. Labetalol, an $\alpha$ and $\beta$ blocker, has also been found to be useful in preventing perioperative undesirable cardiovascular events but in higher doses, it may cause hypotension and bradycardia. With this background we conducted a prospective, randomized, double blind, comparative clinical study of low dose Esmolol versus low dose Labetalol with aims and objectives to study efficacy in preventing stress response to laryngoscopy and intubation and to study various hemodynamic parameters intraoperatively and to study any side effects. 


\section{Materials and Methods}

After getting approval from the institutional ethical committee, a prospective, randomized, double blind study was conducted on 60 ASA 1 patients (30 in each group) of either sex undergoing elective surgeries under general anaesthesia in Orthopedic operation theatre over a period of one year. This was a pilot study with Confidence: 0.95 , Probability: 0.05 so the calculated sample size was 59. We took a rounded figure of 60 . This implied that problems with a prevalence of $5 \%$ will almost certainly be identified (with 98\% confidence) in a pilot study including 59 patients. ASA $1 \& 2$ patients of either sex between age group of 20-50 yrs having height between 150-180centimeters and weight between 50-70 kilograms were included in the study. Patients with extremes of age, or known asthmatic, COPD patients, those having baseline bradycardia or heart block, or on beta blockers were excluded from the study.

Blinding was done using the SNOSE (sequentially numbered opaque sealed envelope) technique. Patients were allocated to any of the two groups-

Group E (Esmolol), Group L (Labetalol) respectively. After confirming nil per oral status and following informed consent, peripheral line was secured with $18 \mathrm{G}$ Veinflon and intravenous fluid Ringers lactate was started. Monitors like Non Invasive Blood Pressure monitor, Electrocardiography leads and pulse oximeter were connected. Group E (Esmolol) received $0.5 \mathrm{mg} / \mathrm{kg}$ diluted with $0.9 \%$ saline to $10 \mathrm{ml}$ intravenously $3 \mathrm{~min}$ prior to intubation. Group L (Labetalol) received $0.25 \mathrm{mg} / \mathrm{kg}$ diluted with $0.9 \%$ saline to $10 \mathrm{ml}$ intravenously $3 \mathrm{~min}$ prior to intubation as per randomization. Along with study drug all patients received premedication with injection Midazolam $0.02 \mathrm{mg} / \mathrm{kg}$, injection fentanyl $[2 \mu \mathrm{g} / \mathrm{kg}]$ was given 5 minutes before induction. Preoxygenation with $100 \%$ Oxygen for 3 minutes was done. All patients were induced with injection Thiopentone $5 \mathrm{mg} / \mathrm{kg}$ intravenously and relaxation achieved by injection Vecuronium $1 \mathrm{mg} / \mathrm{kg}$ intravenously after confirmation of mask ventilation. All intubation were done by well experienced anaesthetist and the same doctor did all the cases to minimize bias. Intraoperatively anaesthesia was maintained by $\mathrm{O}_{2}: \mathrm{N}_{2} \mathrm{O}(1: 1)$ with Isoflurane upto $1.5 \%$. Muscle relaxation was achieved with injection Vecuronium $0.2 \mathrm{mg} / \mathrm{kg}$.
Heart rate (HR), Systolic blood pressure (SBP), Diastolic blood pressure (DBP) Mean arterial pressure (MAP), Rate pressure product (RPP) was measured preinduction, at intubation and at 1,3,5,10 $\mathrm{min}$ post induction by another anaesthetist who was blinded to the study. For statistical analysis heart rate\& Blood Pressure changes $\pm 30 \%$ was considered significant. Statistical analysis was performed using the INSTAT software version 3.10 .The study data were analyzed using statistical methods of mean, standard deviation, paired students " $t$ " test (for values within the group at different time stations) and independent samples " $t$ " test (for comparison of intergroup values).

A $p$ value $<0.05$ was considered significant and $<0.01$ highly significant.

\section{Observation and Result}

Data was collected in master chart and statistical analysis was done. Demographically both groups were similar and there was no significant difference. Duration of surgery was similar in both groups with $\mathrm{P}$ value of 0.8 suggesting that same type of cases were included in the study. Cases were done by an experienced anaesthetist and all intubations were performed by the same person to minimize bias and were done in almost same time of 11-13 sec in both the groups. Both groups had similar pulse rates before induction but at intubation and 1, 3,5,10 $\mathrm{min}$ post intubation there was significant difference (P Value < 0.05 ) with Labetalol group having lower pulse rates at all times thus achieving better control than Esmolol. Systolic blood pressure between two groups remained same before intubation but at intubation and 1, 3, 5, 10 min following intubation results were in favor of Labetalol group which had lower values as compared to Esmolol group (P Value < 0.05). On the other hand diastolic blood pressures did not show much difference either pre or post intubation and we concluded that both the drugs didn't have much effect on diastolic blood pressures. Mean arterial pressure were similar in both groups at all times except 1 min post intubation where it was lower in Labetalol group ( $\mathrm{P}$ Value $<0.05)$. Rate pressure product (Heart Rate X Systolic Blood Pressure) shows decreased values in Labetalol group as compared to Esmolol group and was statistically significant $(\mathrm{P}$ Value $<0.05)$ at all times except preinduction.

Table 1: Demographic profile, duration of surgery $\&$ intubation time

\begin{tabular}{|l|c|c|c|}
\hline \multicolumn{1}{|c|}{ Parameters } & $\begin{array}{c}\text { Esmolol(E) } \\
\text { Mean } \pm \text { SD }\end{array}$ & $\begin{array}{c}\text { Labetalol(L) } \\
\text { Mean } \pm \text { SD }\end{array}$ & P Value \\
\hline Age & $33 \pm 5.40$ & $33.4 \pm 5.32$ & 0.7736 \\
\hline Weight(KG) & $54.26 \pm 3.46$ & $54.4 \pm 3.60$ & 0.8844 \\
\hline Height(CM) & $159.83+3.16$ & $159.63+2.89$ & 0.7993 \\
\hline Sex(M/F) & $15 / 15$ & $15 / 15$ & 1 \\
\hline $\begin{array}{l}\text { Duration of } \\
\text { Surgery(MIN) }\end{array}$ & $95.66 \pm 9.25$ & $96.16 \pm 8.57$ & 0.8290 \\
\hline Intubation Time(SEC) & $11.76 \pm 1.95$ & $12 \pm 1.87$ & 0.6393 \\
\hline
\end{tabular}


Table 2: Pulse Rate

\begin{tabular}{|c|c|c|c|}
\hline Pulse rate & Group E (min) & Group L (min) & P value \\
\hline Preinduction & $85.76 \pm 8.33$ & $85.24 \pm 14.26$ & 0.876 \\
\hline At intubation & $108.64 \pm 11.1$ & $97.4 \pm 9.01$ & $<0.001$ \\
\hline Post Intubation & & \\
\hline 1 min & $109.64 \pm 8.57$ & $98.16 \pm 10.6$ & $<0.001$ \\
\hline $3 \mathrm{~min}$ & $97.44 \pm 9.17$ & $90.56 \pm 11.03$ & 0.020 \\
\hline $5 \mathrm{~min}$ & $93.68 \pm 12.25$ & $85.28 \pm 11.35$ & 0.015 \\
\hline $10 \mathrm{~min}$ & $90.16 \pm 11.23$ & $76.16 \pm 7.76$ & $<0.001$ \\
\hline
\end{tabular}

Table 3: Systolic Blood Pressure

\begin{tabular}{|c|c|c|c|}
\hline & Group E (mm Hg) & Group L (mm Hg) & P value \\
\hline Preinduction & $121.04 \pm 9.14$ & $126.08 \pm 10.57$ & 0.078 \\
\hline $\begin{array}{c}\text { At } \\
\text { Intubation }\end{array}$ & $154.24 \pm 17.35$ & $140.72 \pm 16.99$ & 0.008 \\
\hline Post Intubation & \multicolumn{3}{|l}{} \\
\hline 1 min & $158.72 \pm 16.77$ & $139.36 \pm 12.56$ & $<0.001$ \\
\hline 3 min & $137.44 \pm 16.44$ & $125.04 \pm 11.33$ & 0.003 \\
\hline 5 min & $127.36 \pm 14.62$ & $118.32 \pm 10.12$ & 0.014 \\
\hline 10 min & $121.68 \pm 9.12$ & $113.68 \pm 11.3$ & 0.008 \\
\hline
\end{tabular}

Table 4: Diastolic Blood Pressure

\begin{tabular}{|c|c|c|c|}
\hline & Group E (mm Hg) & Group L (mm Hg) & $\begin{array}{c}P \text { value } \\
\text { E and L }\end{array}$ \\
\hline Pre induction & $79.12 \pm 6.9$ & $81.28 \pm 5.82$ & 0.238 \\
\hline At intubation & $98.8 \pm 6.95$ & $100.64 \pm 13.67$ & 0.551 \\
\hline Post intubation & \multicolumn{3}{|}{} \\
\hline 1 min & $94.96 \pm 6.48$ & $97.52 \pm 9.92$ & 0.286 \\
\hline 3 min & $87.36 \pm 6.23$ & $89.76 \pm 6.61$ & 0.193 \\
\hline 5 min & $82.40 \pm 6.29$ & $82.80 \pm 9.11$ & 0.857 \\
\hline $10 \mathrm{~min}$ & $78.96 \pm 6.80$ & $79.04 \pm 7.53$ & 0.969 \\
\hline
\end{tabular}

Table 5: Mean Arterial Pressure

\begin{tabular}{|c|c|c|c|}
\hline $\begin{array}{c}\text { Mean Arterial } \\
\text { Presssure }\end{array}$ & $\begin{array}{c}\text { Group E } \\
(\mathbf{m m ~ H g})\end{array}$ & $\begin{array}{c}\text { Group L } \\
(\mathbf{m m ~ H g})\end{array}$ & $\begin{array}{c}\text { P value E } \\
\text { and L }\end{array}$ \\
\hline Preinduction & $93.09 \pm 7.03$ & $96.21 \pm 5.80$ & 0.094 \\
\hline At intubation & $117.28 \pm 8.53$ & $114.00 \pm 13.33$ & 0.305 \\
\hline Post intubation \\
\hline 1 min & $116.21 \pm 6.90$ & $111.46 \pm 9.01$ & 0.042 \\
\hline $3 \mathrm{~min}$ & $104.05 \pm 8.09^{*}$ & $101.52 \pm 6.71$ & 0.234 \\
\hline $5 \mathrm{~min}$ & $97.38 \pm 8.08$ & $94.64 \pm 8.36$ & 0.244 \\
\hline $10 \mathrm{~min}$ & $93.2 \pm 6.74$ & $90.58 \pm 8.12$ & 0.222 \\
\hline
\end{tabular}

Table 6: Rate Pressure Product

\begin{tabular}{|l|c|c|c|}
\hline \multicolumn{1}{|c|}{ RPP } & $\begin{array}{c}\text { Group E } \\
(\mathbf{m m ~ H g} / \mathbf{m i n})\end{array}$ & $\begin{array}{c}\text { Group L } \\
(\mathbf{m m} \text { Hg /min })\end{array}$ & $\boldsymbol{P}$ value \\
\hline Preinduction & $10420 \pm 1562$ & $10726 \pm 1889$ & 0.535 \\
\hline At intubation & $16894 \pm 3203$ & $13719 \pm 2136$ & $<0.001$ \\
\hline Post intubation & \multicolumn{3}{|l|}{} \\
\hline 1 min & $17471 \pm 2746$ & $13647 \pm 1769$ & $<0.001$ \\
\hline 3 min & $13438 \pm 2325$ & $11336 \pm 1846$ & 0.007 \\
\hline 5 min & $11995 \pm 2468$ & $10143 \pm 1938$ & 0.001 \\
\hline 10 min & $11017 \pm 1957$ & $8680 \pm 1401$ & $<0.001$ \\
\hline
\end{tabular}




\section{Discussion}

Laryngoscopy and intubation may be associated with various dysrhythmias which are generally transient

and well tolerated by healthy patients, ${ }^{1}$ but it may be fatal for a patient with known cardiac disease. So most clinicians use adjuncts to attenuate the sympathetic response in high risk patients. Beta blockers have been compared with Fentanyl, ${ }^{3,4}$ Nitroprusside, ${ }^{5}$ Nitroglycerine, ${ }^{6}$ calcium channel blockers, ${ }^{7}$ etc. However, studies comparing Esmolol $^{8-11}$ (cardioselective beta blocker) and Labetalol ${ }^{12}$ (nonselective adrenergic blocker) are few. Esmolol hydrochloride is an ultra-short acting, beta-one selective adrenergic receptor blocker with a distribution half-life of 2 minutes and an elimination half-life of 9 minutes. It is suitable for use during a short-lived stress such as tracheal intubation. Labetalol is an adrenergic receptor blocking agent with mild alphal and predominant beta-adrenergic receptor blocking actions (alpha: beta blockade ratio of 1:7 for intravenous and 1:3 for oral administration). Equipotent dose of esmolol is approximately 10 times of labetalol dose.

The onset of action of intravenous Labetalol is 5 minutes. With this background we conducted this prospective, randomized, comparative clinical study, using Esmolol $(0.5 \mathrm{mg} / \mathrm{kg})$ and Labetalol $(0.25 \mathrm{mg} / \mathrm{kg})$ given 2 minutes and 5 minutes prior to intubation respectively.

We studied the hemodynamic response to laryngoscopy and intubation for a period of 10 minutes as this is the average period for which hemodynamic changes are believed to last.

Labetalol had a significantly $(P<0.05)$ better effect than Esmolol in controlling pulse rate at all points during the study. Esmolol showed no significant effect on pulse rate. When instrumentation stimulus is present Labetalol maintains the pulse rates within normal ranges. After 10 minutes post intubation when stimulus effect weans off the drug's effect takes over and pulse rates go below baseline values.

In preventing the increases in systolic Blood Pressure Esmolol was completely ineffective. Labetalol prevented the increase in SBP significantly throughout the study period $(P<0.05)$. Ramanathan et al $l^{13}$ used 20 $\mathrm{mg}$ Labetalol to prevent rise in SBP successfully. As per Inada et al [14], $10 \mathrm{mg}(0.14 \mathrm{mg} / \mathrm{kg})$ Labetalol was ineffective in attenuating the rise in systolic pressure. This difference could be the result of lower doses used and timing of drug administration

Maharaj et al. ${ }^{15}$ failed to blunt the blood pressure response with 0.25 and $0.5 \mathrm{mg} / \mathrm{kg}$ labetalol. However, they did not mention the timing of giving the drug. Esmolol even in doses exceeding $>1 \mathrm{mg} / \mathrm{kg}$ have been found to be ineffective in controlling systolic pressure rise.

Derbyshire DR et al stated that tracheal intubation is accompanied by sympathetic and sympathoadrenal activity so suppression of pressor response requires both alpha and beta adrenergic blockade. ${ }^{16}$ In our study we got the same results as labetalol causing both alpha and beta lockade scored over beta-1 selective esmolol in preventing pressor response.

Diastolic blood pressure was not attenuated $(P>0.05)$ in any of the study groups. No significant difference was observed in intergroup comparison of Esmolol and Labetalol, $(P>0.05)$. Between Esmolol and Labetalol there was no significant difference in values except at 1 minute postintubation (Labetalol having lower MAPs, $P<0.04)$. This observation was again an isolated finding and no significant difference $(P>0.05)$ was found at any other point during the study period. MAP increase was attenuated by Labetalol but not Esmolol.

RPP is an index of myocardial oxygen consumption. ${ }^{17}$ It is the product of SBP and HR. Values in excess of 15,000 are considered critical. Increase in RPP due to increase in HR is potentially more deleterious than that due to increase in blood pressure. ${ }^{8,18}$ In Esmolol-treated patients Rate Pressure Product(RPP) was not significantly different from the control group. Compared to Esmolol groups, the Labetalol group had significantly lower values of RPP. Labetalol could not prevent the increase in RPP completely, but values never crossed the critical limit of $15000 \mathrm{mmHg} / \mathrm{min}$. The values returned to baseline at 3 min post intubation as compared to other group where baseline values were achieved at $10 \mathrm{~min}$. Therefore, Labetalol $(0.25 \mathrm{mg} / \mathrm{kg})$ decreases the magnitude and duration of hemodynamic response to laryngoscopy as evident from changes of RPP. Leslie et al. ${ }^{19}$ used Labetalol in doses of $0.25,0.5,0.75$ and $1.0 \mathrm{mg} / \mathrm{kg}$ and found all doses effective in controlling the rise in RPP at laryngoscopy.

Labetalol caused bradycardia intraoperatively in seven patients $(28 \%)$ (Pulse rate $<50$ beats per minute) after the study period of $10 \mathrm{~min}$. Atropine $0.6 \mathrm{mg}$ was given and all the patients responded well. There were no recurrent episodes of bradycardia. No other side effects were observed. There were no abnormal ECG changes between the duration of induction and intubation.

\section{Conclusion}

From our study we concluded that in lower doses, Labetalol $(0.25 \mathrm{mg} / \mathrm{kg})$ is more effective than Esmolol $(0.5 \mathrm{mg} / \mathrm{kg})$ in attenuating the sympathomimetic response to laryngoscopy and intubation. Bradycardia is a potential side effect of Labetalol which is easily treatable.

\section{References}

1. King BD, Harris LC Jr, Griefenstein FE, Elder JD Jr. Reflex circulatory responses to direct laryngoscopy and intubation performed during Anaesthesia. Anaesthesiology 1951; 12:556-66. 
2. Takki S et al. effect of Laryngoscopy and Intubation on plasma catecholamine levels during intravenous induction of Anaesthesia. Br J Anaesth, 44;1323-28,1972.

3. Cork RC et al, Fentanyl preloading for rapid sequence of Anaesthesia. Anaesth Analg 63:60-64,1984.

4. Martin DE, Rosenberg H, Aukburg SJ, Bartkowski RR, Edwards MW Jr, Greenhow DE, et al. Low dose Fentanyl blunts circulatory responses to tracheal intubation. Anesth Analg 1982;61:680-4.

5. Stoelting RK. Attenuation of blood pressure response to Laryngoscopy and tracheal intubation with Sodium Nitroprusside. Anesth Analg 1979;58:116-9.

6. Kamra S, Wig J, Sapru RP. Topical Nitroglycerine. A safeguard against pressor response to tracheal intubation. Anaesthesia 1986;41:1087-91.

7. Mikawa K, Nishina K, Maekawa M, Obara H. Comparison of Nicardipine, Diltiazem and Verapamil for controlling the cardiovascular responses to tracheal intubation. Br J Anaesth 1996;76:221-6.

8. Ebert TJ, Bernstein JS, Stowe DF, Roerig D, Kampine JP. Attenuation of hemodynamic responses to rapid sequence induction and intubation in healthy patients with a single bolus of Esmolol. J Clin Anesth 1990;2:243-52.

9. Rathore A, Gupta HK, Tanwar GL. Attenuation of the pressure response to Laryngoscopy and Endotracheal intubation with different doses of Esmolol. Indian J. Anaesth 2002;46:449-52.

10. Oda Y, Nishikawa K, Hase I, Asada A. The short-acting ß1-Aadrenoceptor antagonists Esmolol and Landiolol suppress the bispectral index response to tracheal intubation during Sevoflurane anaesthesia. Anesth Analg 2005;100:733-7.

11. Oxorn D, Knox JW and Hill J. Bolus doses of Esmolol for the prevention of perioperative hypertension and tachycardia. Can J Anaesth 1990;37:206-09.

12. Kim HY, Chung CW, Lee HY, Yim CH. The Effect of Labetalol on the hemodynamic response to Endotracheal intubation. Korean J Anesthesiol 1994;27:1611-9.

13. Ramanathan J, Sibai BM, Madie WC, Chauhan D, Ruiz AG. The use of Labetalol for attenuation of hypertensive response to Endotracheal intubation in preeclampsia. Am J Obstet Gynecol 1988;159:650-4.

14. Inada E, Cullen D J, Nemeskal R, Teplick R. Effect of Labetalol on the hemodynamic response to intubation: a controlled, randomized double-blind study. J Clin Anesth 1989;1:207-13.

15. Maharaj RJ, Thompson M, Brock JG, Williamson R, Downing JW. Treatment of hypertension following Endotracheal intubation. A study comparing the efficacy of Labetalol, Practolol and placebo. S Afr Med J 1983;63:691-4.

16. Derbyshire DR et al. plasma catecholamine response to tracheal intubation. Br J Anaesth; 1983;55(9):855-6.

17. Kissin I, Reves JG, Mardis M. Is the rate-pressure product a misleading guide? Anesthesiology. 1980;52:373-4.

18. Wilkinson PL, Myers JR, Ports T. Rate pressure product and myocardial oxygen consumption during surgery for coronary bypass. Circulation. 1979;60:170-3.

19. Leslie JB, Kalayjian RW, Mc Loughlin TM, Plachetka JR. Attenuation of hemodynamic response to Endotracheal intubation with pre induction intravenous Labetalol. J Clin Anesth 1989;1:194-200. 